\title{
Critical infrastructure impact assessment due to flood exposure
}

Authors:

Raghav Pant (Corresponding Author)

Environmental Change Institute, University of Oxford, Oxford, UK

Email: raghav.pant@,ouce.ox.ac.uk

Scott Thacker

Environmental Change Institute, University of Oxford, Oxford, UK

Email: scott.thacker@,ouce.ox.ac.uk

Jim W. Hall

Environmental Change Institute, University of Oxford, Oxford, UK

Email: jim.hall@eci.ox.ac.uk

David Alderson

School of Civil Engineering and Geosciences, Newcastle University, UK

Email: david.alderson@ncl.co.uk

Stuart Barr

School of Civil Engineering and Geosciences, Newcastle University, UK

Email: stuart.barr@ncl.co.uk

Journal: Journal of Flood Risk Management - Special Issue: Land for Flood Risk

Management, A catchment-wide and multi-level perspective

Word count $=5665$ (excluding references)

\section{Abstract}

Critical national infrastructures, including energy, transport, digital communications and water, are prone to flood damage. Their geographical extent is a determinant of, and is determined by, patterns of human development, which is often concentrated in floodplains. It is important to understand how infrastructure systems react to large-scale flooding. In this paper we present an integrated framework for critical infrastructure flood impact assessment. Within this integrated framework we represent interdependent infrastructure assets through spatial network models. We quantify infrastructure flood impacts in terms of disrupted customers linked directly to flood assets and customers disrupted indirectly due to network effects. The analysis shows how spatial network models inform flood risk management practitioners to identify and compare critical infrastructures risks on flooded and non-flooded land, for prioritising flood protection investments and improve resilience of cities. A case study of the Thames catchment in England is presented, which contains key infrastructure assets and highest population concentrations in United Kingdom.

Keywords: Critical infrastructures, Customer disruptions, Flood catchment, Flood hazard, Infrastructure Networks, Vulnerability, Risks.

This article has been accepted for publication and undergone full peer review but has not been through the copyediting, typesetting, pagination and proofreading process, which may lead to differences between this version and the Version of Record. Please cite this article as doi: $10.1111 /$ jfr3.12288 


\section{Introduction}

Civil infrastructures, such as electricity grids, roads, railways, ports, airports, water, ICT, are the physical backbone of modern societies, as they are essential for the continued delivery of goods and services and maintaining economic and social well-being. In Great Britain (GB), where our study area lies, civil infrastructures are classified as 'critical national infrastructures' because their failures could lead to "serious consequences, including severe economic damage, grave social disruption, or even large scale loss of life" (Cabinet Office 2010).

Extreme weather events pose serious risks to critical national infrastructures in GB. Flooding has been identified as the greatest risk to GB, both currently and in future climate change exacerbated scenarios (ICE 2009). In England and Wales there are currently around 50,000 hectares of land that are classified as at risk of frequently flooding (at least once in every three years), which is projected to increase to around 200,000 hectares by the 2080s (HM Government 2012). There is increased focus in GB on flood risk assessment to reduce socioeconomic risks and enhance resilience (HM Government 2011; ASC 2014). Flood risk assessments are also prioritized in national planning documents in United States (Homeland Security 2013), Australia (AECOM 2008), Europe (EC 2007), among others. Due to such continued efforts normalised flood vulnerability and losses across the world have been declining over the last few decades (Barredo 2009; Jongman et al. 2015).

In research there is increased recognition that flood risk assessments need to be integrated with other catchment management objectives (EC 2007; HM Government 2012). One such objective is to prepare cities in a way that they are adapted to flood inundations (resistance/resilience). Several integrated flood risk assessment frameworks have been proposed (Evans et al. 2006; Merz et al. 2010), along with quantifiable examples of catchment-level impacts of flood inundation (Hall et al. 2003; Dawson et al. 2005; Gouldby et al. 2008). Mostly these frameworks provide methods and tools for planning flood defense protection and insurance measures for aggregated number of household or business properties within flood areas. There is very little done in terms of understanding and quantifying flood risks to critical infrastructures and their wider impacts on flood risk management and catchment level planning. There are only a few studies (Pant et al. 2016; Kalantari et al. 2014; Zischg et al. 2005) that address this topic, because network characteristics of infrastructures are recognized but seldom modeled in the analysis (Emanuelsson et al. 2014). In particular representations of infrastructure network interdependencies (or dependencies) (Rinaldi et al. 2001; Rinaldi 2004) in existing flood risk assessment frameworks are mostly 
non-existent. These interdependencies (or dependencies) are crucial for understanding how flood risks propagate across infrastructures and towards society.

The focus of this paper is on modelling the flood inundation impacts on critical infrastructure networks, which leads toward informed flood resilience planning. We present an integrated framework for quantifying wider spatial consequences of infrastructure failures due to flooding. The framework includes: (1) assembling data and models for representing critical infrastructures as spatially interdependent networks; and (2) developing models for mapping customers as flows onto the networks. Within the framework when the spatial network models are subjected to flood hazards we estimate the flood disruption impacts. These are presented in terms of numbers of infrastructure assets and their customers who are directly a risk due to flooding, and infrastructure assets and customers indirectly at risk due to network effects. The methodology is demonstrated through a case study of the Thames catchment floodplain in England, containing some of the most densely populated areas like London supported by infrastructure assets for electricity, water, waste, telecoms and airport sectors in the region.

The integrated framework presented here gives quantitative measures to inform spatial planners and flood risk managers about the locations and spatial extents of risks due to infrastructure failures. Flooding impacts urban areas where several key infrastructures are located. Decisions on where to build houses are now recognised as a key tool in managing future flood risks. The importance of protecting vital infrastructure from flooding is also clear (Wheater \& Evans 2009). Through the integrated framework we can identify which infrastructure assets lie within flooded areas and how many customers are impacted by their failures. We can also identify which infrastructure assets lie outside flooded areas but are disrupted due to their dependence on other flooded assets. Such information is useful in deciding where to target and prioritise flood protection measures, which logically would be around flooded assets that create widespread network disruptions. Ultimately this helps city planners to narrow down and strategize spatial flood management planning for improved resilience to flooding inundations.

In such decision-making it is also important to recognise that flooding creates upstreamdownstream dependency relationships between multiple municipal boundaries based on their location in the flood catchment (Thaler 2014; Seher and Löschner 2015; Thaler et al. 2016) and the propagation of the sediment transport (Bornschein and Pohl 2005). Infrastructure disruptions introduce wider effects due to network failure propagation. There are several notable real-world examples of such infrastructure failures and disruption propagations. Some of these include: (1) In 2011 power failure at a major exchange in Birmingham resulted in the loss of broadband connection for hundreds of thousands of customers across the UK (BBC 2011). (2) During winter 2013 flooding led to the failure of three electricity substations at Gatwick airport disrupting 13,000 airline customers (McMillan 2014). Hence with infrastructures there is a need to understand both vertical and horizontal risk-sharing at a catchment-wide scale to spatially distribute risk decision-making (Seher and Löschner 2015). Through our integrated framework we are able to capture the spatial distribution of the flood risks across multiple boundaries, which inform how the risk could be shared vertically and horizontally across catchments.

The rest of the paper is organised as follows. First we present the integrated framework and explain the mathematical development of the infrastructure network models, customer 
demand assignments and disruption analysis. Next we present the case study for the Thames catchment flooding and its effect on interconnected infrastructures and assets understood in terms of direct and indirect customer disruptions. Finally the conclusions of the analysis are discussed, its possible further developments, and value for flood risk decision-making.

\section{Integrated framework and component models}

In this section we present the integrated framework for critical infrastructure flood impact assessment. We explain the underlying infrastructure network assembly, which includes the mathematical notation for representing the infrastructure network topologies as spatial networks and customer flows assignments. We also explain how network disruptions are estimated.

The end result of the integrated framework is to quantify the potential 'customers at risk' due to widespread flooding. We use the word 'risk' in a qualitative sense to indicate potential negative impacts. We present three categories of risks: (1) Direct risk: the total numbers of customers that are at direct risk of disruptions due to the failure of an asset on which they dependent. For example: electricity customers are directly disrupted by failed electricity assets, airport customers are directly disrupted by failed airport assets. (2) Indirect risk: the total number of customers that are at indirect risk of disruptions due to the failure of the electricity asset for which they are dependent. For example, airport customers are indirectly dependent on electricity assets. (3) Direct and indirect risk: Customers that are at risk to both direct and indirect failures. For example some assets (i.e. water and airport) might be at risk of failure from flooding directly and also at risk of flooding indirectly through loss of electricity supply. To our knowledge such metrics for customer risks are unique to this work. However similar metrics of direct and indirect risks are widely used in estimating economic losses due to flooding (Thieken et al. 2008; Koks et al. 2015).

\section{Integrated framework}

The integrated framework, shown in Figure 1, is presented and explained as following:

A. Hazard estimation - The aim of the component is to assemble data and models for spatial flood hazards. Such hazard information is represented through indicative flood hazards maps that include: (1) the flood footprint - which shows the spatial extent of a flood outline; and (2) the magnitude of the flood hazard - which is given either in terms of likelihood of flood exposure or the magnitude of flooding (either flow volumes or flood depth). In this paper the flood hazard information is available from other sources, hence our aim is not to explain the details of flood modelling.

B. Network estimation - In this component we assemble multiple interconnected national scale infrastructure networks. These models are explained in the next section. The important considerations during network estimation are collecting suitable geospatial and connectivity data, mapping the functional flow paths, and assigning customers to the infrastructures.

C. Infrastructure failure assessment - The final component of the framework is a computational process based on simulating the failures of nodes and edges in networks. In the first instance these failures are initiated based on the direct exposure of network assets to the flood hazard. The customers disrupted by such failures contribute toward direct 
losses. Following such failures, we find all disrupted functional pathways and subsequently find the disrupted customers. This gives us the indirect asset failures and customer losses.

Figure 1 demonstrates a workflow for the implementation of the integrated framework. Infrastructure failure assessment in Component $\mathrm{C}$ follows from Component $\mathrm{A}$ and $\mathrm{B}$ hazard and network model assembly. By setting up a simulation procedure to execute Component $\mathrm{C}$ we can repeat it several times for different assets to generate multiple failure scenario outcomes.

Figure 1: Flowchart showing the integrated assembly of component models and implementation of the models to estimate flood disruptions of critical infrastructure networks.

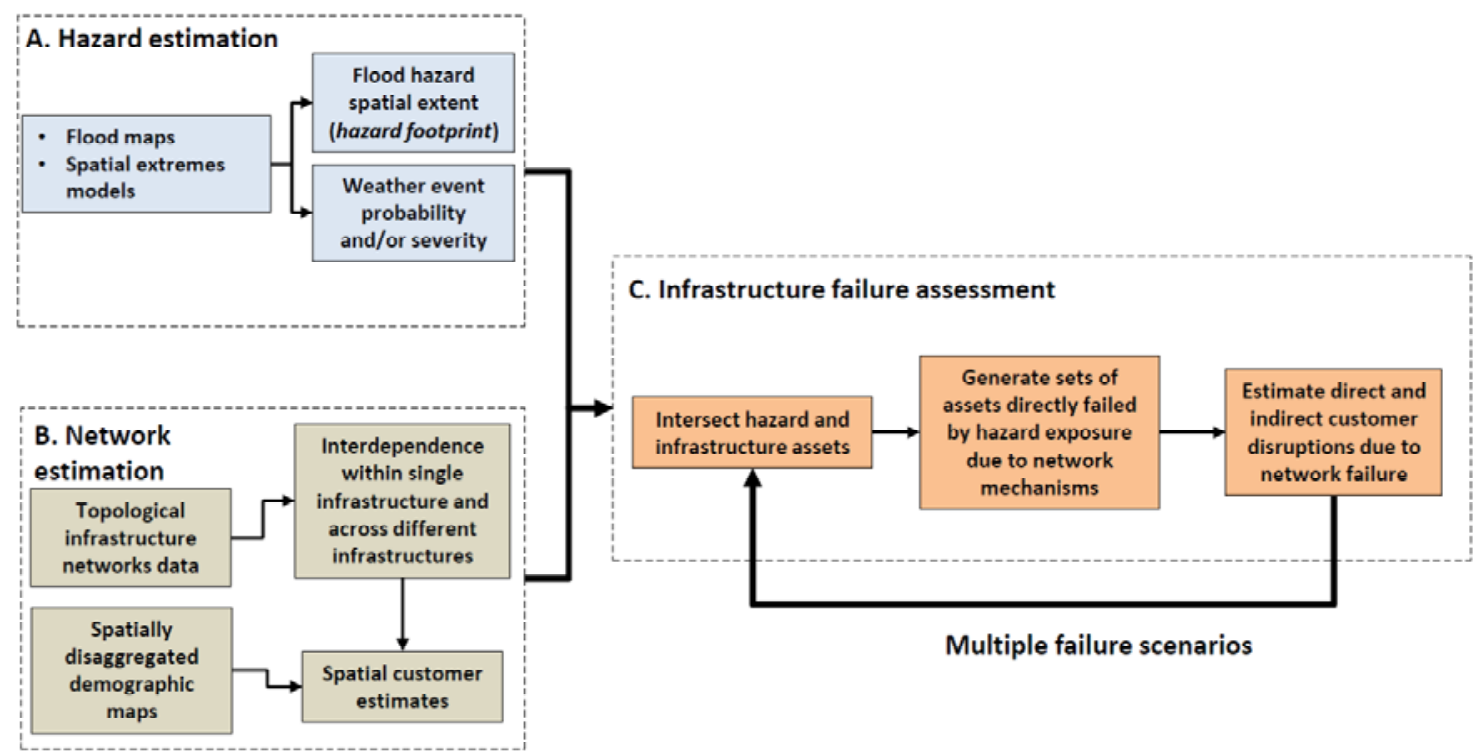

\section{Network assembly}

We assume there are $l$ number of different infrastructures represented by the set $I=$ $\left\{I^{1}, \ldots, I^{l}\right\}$. An individual infrastructure type $I^{i} \in I$ is a network graph, represented as $I^{i} \equiv\left(N^{i}, E^{i i}\right)$, where $N^{i}=\left\{n_{1}^{i}, \ldots, n_{z}^{i}\right\}$ is the set of nodes and $E^{i i}=\left\{e_{j k}^{i i}=\left(n_{j}^{i}, n_{k}^{i}\right) \subseteq N^{i} \times\right.$ $\left.N^{i}\right\}$ is the set of edges, defining the existence and connectivity of all assets belonging only to the infrastructure $I^{i}$. Here $e_{j k}^{i i}=\left(n_{j}^{i}, n_{k}^{i}\right)$ signifies the edge element $e_{j k}^{i i}$ connecting adjacent nodes $n_{j}^{i}$ and $n_{k}^{i}$. Infrastructure $I^{i}$ is also connected to other infrastructures, which is represented by the edge set $E^{i s}=\left\{e_{j k}^{i s}=\left(n_{j}^{i}, n_{k}^{s}\right) \subseteq N^{i} \times N^{s}\right\}$. Overall combining all node and edge sets together, our set of all infrastructures is defined as a network-of-networks $I \equiv(N, E)$, where $N=\left\{N^{1}, \ldots, N^{l}\right\}$ and $E=\left\{E^{i j} \forall i, j \in\{1, \ldots, l\}\right\}$.

While assembling and creating the different infrastructure networks the following properties are incorporated into the network models: (1) The network assets exist in a 2D space defined in terms of a Cartesian coordinate system. Nodes are assigned point coordinates (latitudes, longitudes) to specify their locations; each edge is a collection of point coordinates that form a linear element. (2) All edges are represented as directed edges, which means there is a distinction between different types or quantities of flows in separate directions along the 


\section{Demand assignments}

In this paper demands are modelled in terms of the number of customers (derived from spatial population statistics) connected to networked assets. While in some instances data on the customer demand is available, in several cases simplified models are built to develop estimates for customer estimates. Our model is outlined here.

Customer demand mapping onto assets - In the first instance customers are most immediately connected to sink nodes, hence the first stage of estimating customer demands is to model such connections. Each sink node $n_{S}^{i}$ of an infrastructure type has a unique footprint, which defines the geographical area $A\left(n_{S}^{i}\right)$ it serves and the customer numbers $\left(c_{S}^{i}\right)$ with that area. A representation of this is shown in the Figure 2population areas layer. Among other methods, a simple way of deriving the footprint area is through Delaunay triangulation (Lee and Schachter, 1980) or Voronoi tessellation (Poljansek et al., 2010) methods. We create a triangle or polygon with a sink node at the centroid, which is based on the assumption that the population nearest to it in space will create the sink node's demand. For most types of infrastructures this is a valid assumption, because in reality infrastructure assets are located and connected to their nearest demand centres as this results in the expansion of least energy (or effort) for delivering goods and services. The customer numbers within an area can be estimated through the population census maps which give population density estimates at different spatial disaggregation, which when multiplied by the footprint area $A\left(n_{S}^{i}\right)$ gives the customer numbers $\left(c_{S}^{i}\right)$.

Customer demand mapping onto networks - The intermediate and source nodes also are assigned customers through their connectivity to the sink nodes. This depends upon the network topology information along with other parameters such as the capacity of source (or intermediate) nodes. In general infrastructure network flow models are more complex and depend upon the properties of the type of infrastructure being studied. Here our aim is to present a simple model for mapping flows onto networks, which can be used for disruption analysis. If the sink node $n_{S}^{i}$ is delivering the resources for a source (or intermediate) node $n_{O}^{i}$, then using the network topology the functional path $P\left(n_{O}^{i}, n_{S}^{i}\right)$ of all nodes traversed on the network between $n_{O}^{i}$ and $n_{S}^{i}$ can be traced. All nodes in this path are then assigned the customer number $c_{S}^{i}$. Since any source (or intermediate) node could be supplying to several sink nodes, within capacity limitations and other operational factors, the customers assigned it can be estimated by mapping all the paths through it and summing the customers assigned to each path. This is given by the equation:

$$
c_{O}^{i}=\sum_{\forall P\left(n_{o}^{i}, n_{S}^{i}\right)} w_{o}^{i} c_{S}^{i}
$$

where $w_{o}^{i} \in(0,1]$ is a parameter that indicates proportion of customers being served by the flow along the source-sink path $P\left(n_{O}^{i}, n_{S}^{i}\right)$, creating a weighted flow network.

The Equation (1) formulation shows the mapping of the number of customers of a particular infrastructure to all its assets. These are referred to as the direct customers for the infrastructure sector. We can also map the number of customers of other infrastructure sectors onto each other. These are referred to as the indirect customers for the supplying infrastructure sector. If the source (or intermediate) node $n_{O}^{i}$ of infrastructure $I^{i}$ is connected to the different types of sink nodes $n_{S}^{j}$ of infrastructure types $I^{j}$, then similar to 
Equation (1) all indirect customers of $n_{O}^{i}$ are estimated by summing over all mapped functional paths $P\left(n_{O}^{i}, n_{S}^{j}\right)$ given the proportional weight (influence) of the path $w_{o}^{i j}$ in satisfying customer demand $c_{S}^{j}$

$$
c_{O}^{i j}=\sum_{\forall P\left(n_{O}^{i}, n_{S}^{j}\right)} w_{o}^{i j} c_{S}^{j}
$$

Figure 2 depicts the weighted flows in the network as quantified by Equations (1) and (2). The width of the arrows shows the increased number of customers mapped along paths upwards from the sink to the source layers.

\section{Disruption estimation}

To estimate how disruptions are initiated and spread across different infrastructure systems we extract the information on the hazard footprint $H$, the spatial polygon extent that could affect the infrastructure assets.

When a particular infrastructure asset intersects the flood footprint, and it is considered failed (due to physical damage or operational shutdown), the network characteristics are used to estimate the number of customers affected due to the disruption of service. If a sink node $n_{S}^{i}$ fails then all customer attached to it will stop receiving service, which implies that the disruption will be $\tilde{c}_{S}^{i}=c_{S}^{i}$. For other nodes the number of disrupted customers depends upon the number of affected paths that cannot function due to the failure of any particular asset on that path. Hence for a source (or intermediate) node $n_{O}^{i}$ the number of disrupted customer is estimated as:

$$
\tilde{c}_{O}^{i}=\sum_{\forall \tilde{P}\left(n_{O}^{i}, n_{S}^{i}\right)} w_{o}^{i} c_{S}^{i}
$$

where $\left\{\tilde{P}\left(n_{O}^{i}, n_{S}^{i}\right)\right\}$ is the set of all source-sink paths that can no longer function and hence the number customers, $w_{o}^{i} c_{S}^{i}$, being served along these paths are disrupted.

Similarly the indirect customer disruptions $\tilde{c}_{O}^{i j}$ are estimated by assembling all cross-sector disrupted paths $\left\{\tilde{P}\left(n_{O}^{i}, n_{S}^{j}\right\}\right.$ and summing the affected customers along these paths.

$$
\tilde{c}_{O}^{i j}=\sum_{\forall \tilde{P}\left(n_{O}^{i}, n_{S}^{j}\right)} w_{o}^{i j} c_{S}^{i j}
$$

The disruption analysis is also represented in Figure 2, showing the flood hazard footprints affecting different parts of the network, subsequently disrupting different function paths. It is noted here that in our modelling network disruptions have a bi-directional propagation because any asset failed 'upstream' or 'downstream' in a network disables the functionality of the whole path.

\section{Case-study}

\section{Data and model assembly}

A catchment-wide flood impact analysis for a collection of infrastructures networks and assets is presented. The area of study is the indicative floodplain for the Thames catchment in England. Figure 1 shows the floodplain map of the Thames catchment, which has an estimated area of $1,600 \mathrm{~km}^{2}$ spread over $16,000 \mathrm{~km}^{2}$ of Local Enterprise Partnerships (LEPs) 
such as London, Oxfordshire, Buckinghamshire, Berkeshire. LEPs are collections of local authorities that participate together for shared common interests in economic developments within their local areas. The LEP's within the Thames catchment contain some of the highest population densities and demands in the UK, especially in the London LEP. The indicative floodplain map for this area is extracted from the National Flood Risk Assessment (NaFRA) flood likelihood map data, which gives likelihood of flooding to areas of land within the flood plain of 1 in 1000 fluvial and tidal flooding scenario. Overall the NaFRA indicative flood give estimated likelihood of flooding accounting for the probability that the flood defences will overtop or breach. The flood footprints are presented for three flood likelihood risk categories as: (1) low - the chance of flooding each year is 0.5 per cent ( 1 in 200) or less, (2) moderate - the chance of flooding in any year is 1.3 per cent ( 1 in 75$)$ or less but greater than 0.5 per cent ( 1 in 200), and (3) significant - the chance of flooding in any year is greater than 1.3 per cent ( 1 in 75 ). In Figure 1 the flood footprints $H$ for low, medium, significant likelihoods are shown.

Figure 1: Representation of the Thames catchment with the hazard footprints for the low, medium and significant flood likelihoods. Also shown in the background are the local enterprise partnerships within and outside to Thames flood catchment.

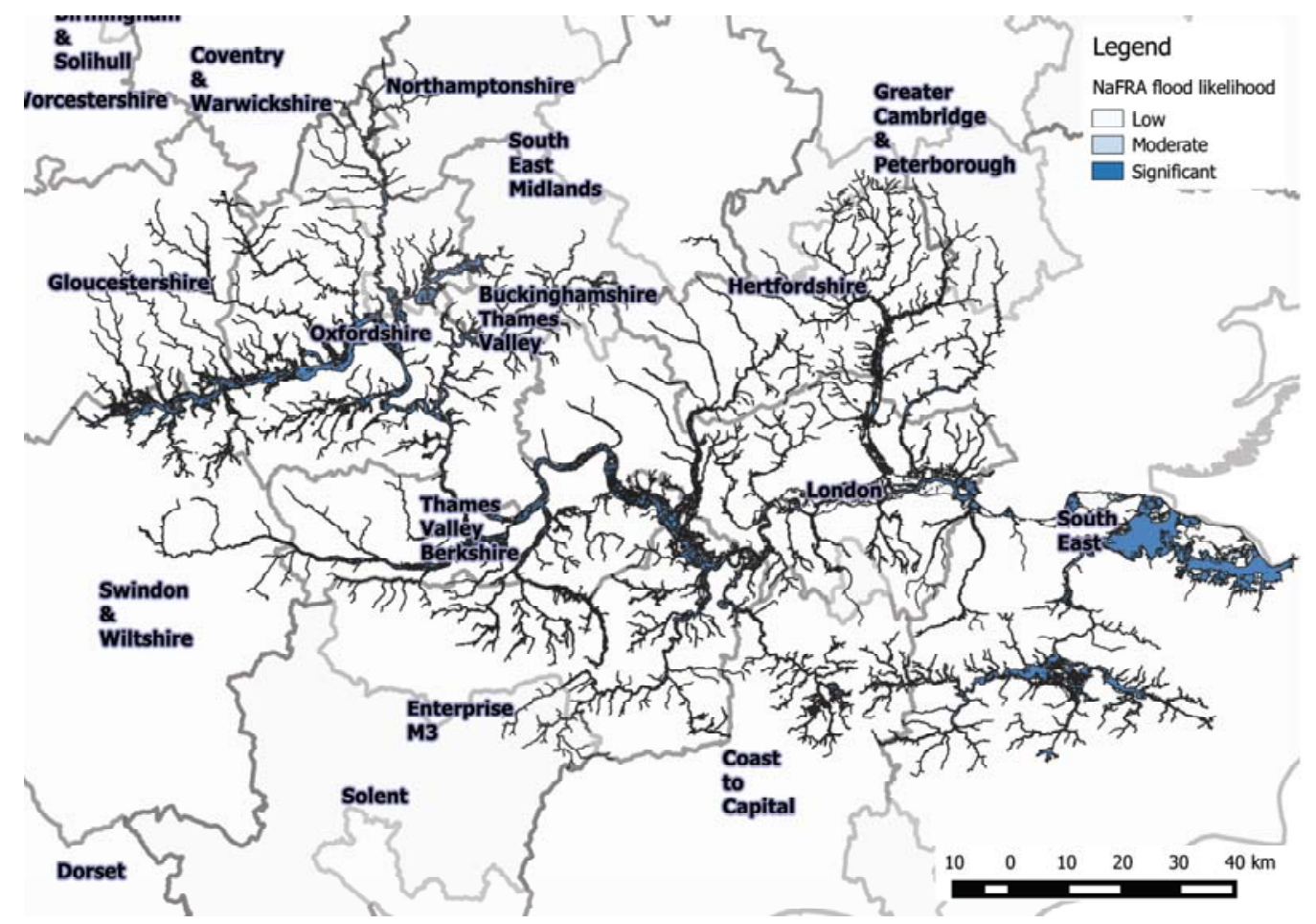

The infrastructure data for this study has been extracted from a bigger database complied at the Great Britain national scale. In this study the infrastructure assets belonging to $I=$ \{electricity, airports, ports, water, and wastewater, telecommunications\} are used. Table 1 lists the infrastructure datasets used, further details of these and the network assembly are given in Thacker et al. (2015). All the data are assembled, created and analysed on a spatial database platform Postresql, using Python programming tools, and GIS tools like QGIS. 
Table 1: List of assets included in the spatial criticality analysis. Detailing the data sources used to complete the spatial topological network representations and the capacity and demand data used to estimate the functional path set and assign customer demands.

\begin{tabular}{|c|c|c|}
\hline Sector & $\begin{array}{c}\text { Spatial and Topological } \\
\text { Attributes }\end{array}$ & $\begin{array}{c}\text { Capacity and Demand } \\
\text { Attributes }\end{array}$ \\
\hline $\begin{array}{c}\text { Electricity generation } \\
\text { - Nodes: } 207\end{array}$ & $\begin{array}{l}\text { Derived using DECC } 2012 \\
\text { DUKES data (DECC, 2012) }\end{array}$ & $\begin{array}{l}\text { Derived using DECC } 2012 \\
\text { DUKES data (DECC, 2012) }\end{array}$ \\
\hline $\begin{array}{l}\text { Electricity transmission } \\
\begin{array}{l}\text { - } \quad \text { Voltage: } 400 \mathrm{kV}, 275 \mathrm{kV} \text {, } \\
132 \mathrm{kV} \\
\text { - Nodes: } 437\end{array}\end{array}$ & $\begin{array}{l}\text { National Grid - derived using } \\
10 \text { year statement (National } \\
\text { Grid, 2012) }\end{array}$ & $\begin{array}{l}\text { Estimated using capacity } \\
\text { constrained location-allocation } \\
\text { path model }\end{array}$ \\
\hline $\begin{array}{l}\text { Electricity sub-transmission } \\
\text { - Voltage: } 132 \mathrm{kV}, 33 \mathrm{kV} \\
\text { - Nodes: } 4798\end{array}$ & $\begin{array}{l}\text { Synthetic - recreated using } \\
\text { inference from known } \\
\text { localized network data and } \\
\text { ordnance survey data (2013) }\end{array}$ & $\begin{array}{l}\text { Estimated using capacity } \\
\text { constrained location-allocation } \\
\text { path model }\end{array}$ \\
\hline $\begin{array}{l}\text { Electricity Distribution } \\
\text { - } \quad \text { Voltage: } 33 \mathrm{kV}, 11 \mathrm{kV}, \\
\text { - } \quad \text { Nodes: } 164,069\end{array}$ & $\begin{array}{l}\text { Synthetic - recreated using } \\
\text { inference from known } \\
\text { localized network data and } \\
\text { ordnance survey data } \\
\text { (Ordnance Survey, 2013) }\end{array}$ & $\begin{array}{l}\text { Estimated using Voronoi } \\
\text { decomposition }\end{array}$ \\
\hline $\begin{array}{l}\text { Airports } \\
\text { - Nodes: } 32\end{array}$ & $\begin{array}{l}\text { Network derived from CAA } \\
2010 \text { statistics (CAA, 2010) }\end{array}$ & $\begin{array}{l}\text { Demands derived directly from } \\
\text { CAA } 2010 \text { statistics (CAA, } \\
\text { 2010) }\end{array}$ \\
\hline $\begin{array}{l}\text { Water towers } \\
\text { - Nodes: } 2566\end{array}$ & $\begin{array}{l}\text { Obtained from Ordinance } \\
\text { Survey }(2013)\end{array}$ & $\begin{array}{l}\text { Estimated using Voronoi } \\
\text { decomposition - detailed in } \\
\text { paper }\end{array}$ \\
\hline $\begin{array}{c}\text { Waste-water treatment } \\
\text { - Nodes: } 1563\end{array}$ & $\begin{array}{l}\text { Obtained from Ordinance } \\
\text { Survey (2013) }\end{array}$ & $\begin{array}{l}\text { Estimated using Voronoi } \\
\text { decomposition }\end{array}$ \\
\hline $\begin{array}{l}\text { Telecom masts } \\
\text { - Nodes: } 5226\end{array}$ & $\begin{array}{l}\text { Obtained from Ordinance } \\
\text { Survey (2013) }\end{array}$ & $\begin{array}{l}\text { Estimated using Voronoi } \\
\text { decomposition }\end{array}$ \\
\hline
\end{tabular}

The electricity infrastructure is modelled as a network, where nodes are used to represent power generation facilities and electricity substations (of different voltages) and edges are used to represent overhead lines and underground cables. We look at the flood exposure of this network within the Thames catchment area. All other infrastructure assets, airports, water assets, wastewater treatment plants and telecommunication towers, are represented as single point nodes. For each asset of these specific infrastructure types the dependence on electricity is considered, by building physical connecting edges between the electricity network nodes and other infrastructure's chosen asset. This physical connectivity is inferred by mapping the geographically closest electricity substation of proper voltage to the infrastructure asset. For example an airport is mapped to its closet $33 \mathrm{kV}$ electricity substation as that is the correct substation supply voltage needed to satisfy its demand. Figure 2 shows an abstract representation of the infrastructure network model discussed above. 

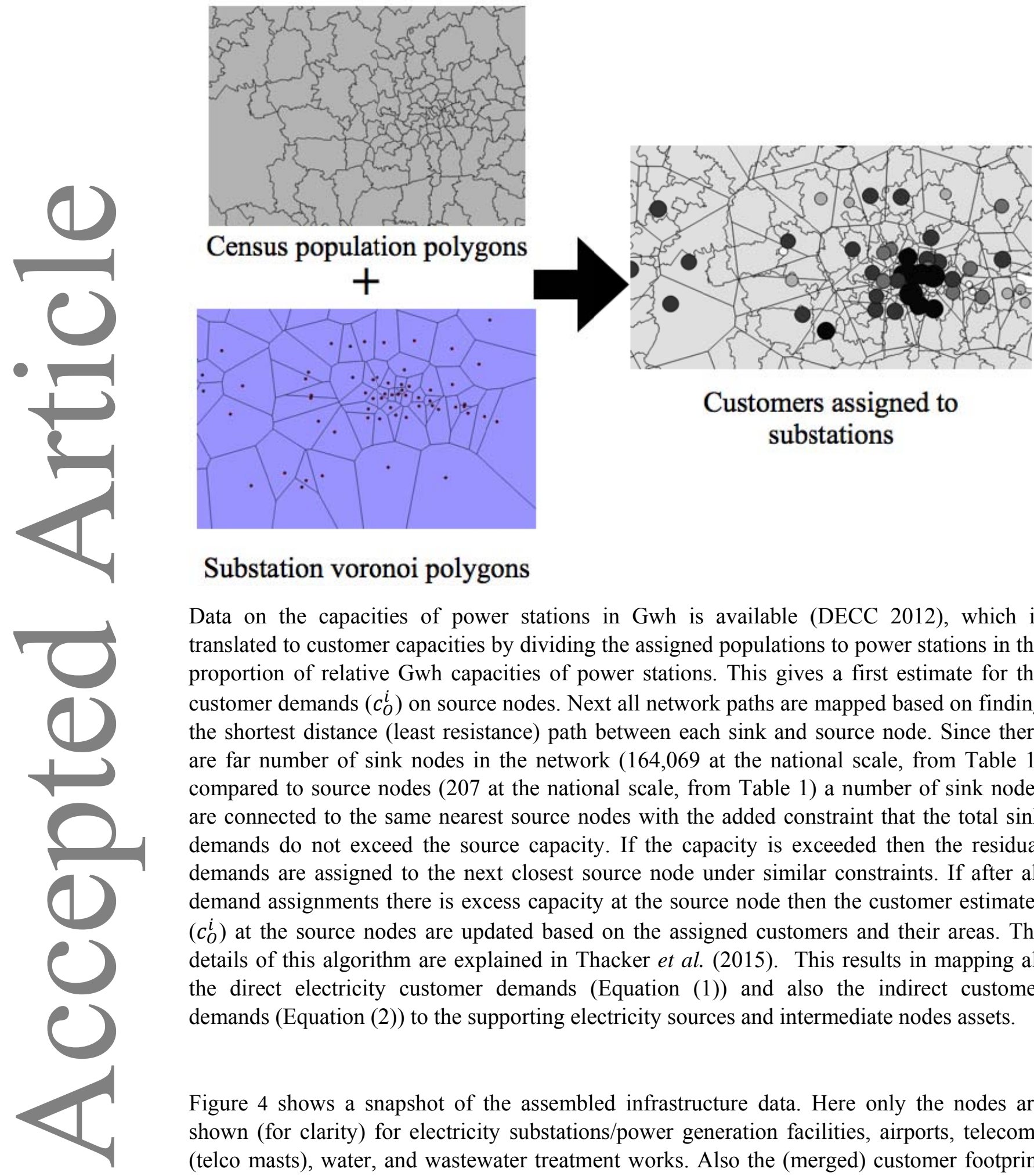

\section{Customers assigned to substations}

\section{Substation voronoi polygons}

Data on the capacities of power stations in Gwh is available (DECC 2012), which is translated to customer capacities by dividing the assigned populations to power stations in the proportion of relative Gwh capacities of power stations. This gives a first estimate for the customer demands $\left(c_{O}^{i}\right)$ on source nodes. Next all network paths are mapped based on finding the shortest distance (least resistance) path between each sink and source node. Since there are far number of sink nodes in the network (164,069 at the national scale, from Table 1) compared to source nodes (207 at the national scale, from Table 1) a number of sink nodes are connected to the same nearest source nodes with the added constraint that the total sink demands do not exceed the source capacity. If the capacity is exceeded then the residual demands are assigned to the next closest source node under similar constraints. If after all demand assignments there is excess capacity at the source node then the customer estimates $\left(c_{O}^{i}\right)$ at the source nodes are updated based on the assigned customers and their areas. The details of this algorithm are explained in Thacker et al. (2015). This results in mapping all the direct electricity customer demands (Equation (1)) and also the indirect customer demands (Equation (2)) to the supporting electricity sources and intermediate nodes assets.

Figure 4 shows a snapshot of the assembled infrastructure data. Here only the nodes are shown (for clarity) for electricity substations/power generation facilities, airports, telecoms (telco masts), water, and wastewater treatment works. Also the (merged) customer footprint (Voronoi polygons) for sets of assets are shown in the background, which is derived based on their connectivity. The flood footprints are also included to provide a sense of the extent of flooding and its intersection with the infrastructure assets. 
to electricity infrastructure due to flooding, and approximately 1.8 times more customers at moderate risk of disruption to electricity infrastructure due to flooding, compared to the significant risk of disruption to electricity infrastructure due to flooding.

\section{Waste Water Treatment Works (WWTW) risk:}

Cumulatively WWTW have the largest risks because large numbers of such assets are located directly in flood areas, as expected due to function. Significant proportions of the WWTW are at risk both directly and indirectly.

\section{Water (towers) risk:}

Water storage assets are found to be located away from flood zones or at elevation, as expected due to function. Hence they have relatively lesser flooding risks. Most of the water risks are indirect risks, due to the failure of the electricity substation supply to the connected water tower. Though there is potentially high susceptibility to electricity loss, in reality water towers many have storage to buffer demand.

\section{Telecom masts risk:}

Similar to water storage assets, telecom assets are also found to be located away from flood zones or at elevation, as expected due to function. Like water, telecom also a potentially high susceptibility to electricity loss. But unlike water the telecoms towers do not have suffer capacity and can be instantaneous 'shut-down' due to electricity outages. However due to the presence of several assets (generally in a mesh structure) in reality there is highly redundancy built in telecoms, which could potentially counter disruptions.

\section{Airports:}

Within the Thames catchment, airports are relatively the least affected. One reason is that their daily passenger numbers are fewer compared to the demand of other assets, hence the disruptions number are low. However airport disruptions can potentially have much wider social and economic consequences, as important airports such as Heathrow, Gatwick are included here. Mostly airport are affected indirectly due to electricity failure, which is reflective of the real situation of London airports at risk to indirect failure (McMillan 2014).

Figure 5: Estimated number of aggregated customers within the Thames flood catchment who are at risk directly, indirectly and both due to potential infrastructures being flooded and disrupted. Here the indirect effects are estimated with respect to the disruption of electricity to other dependent assets. 

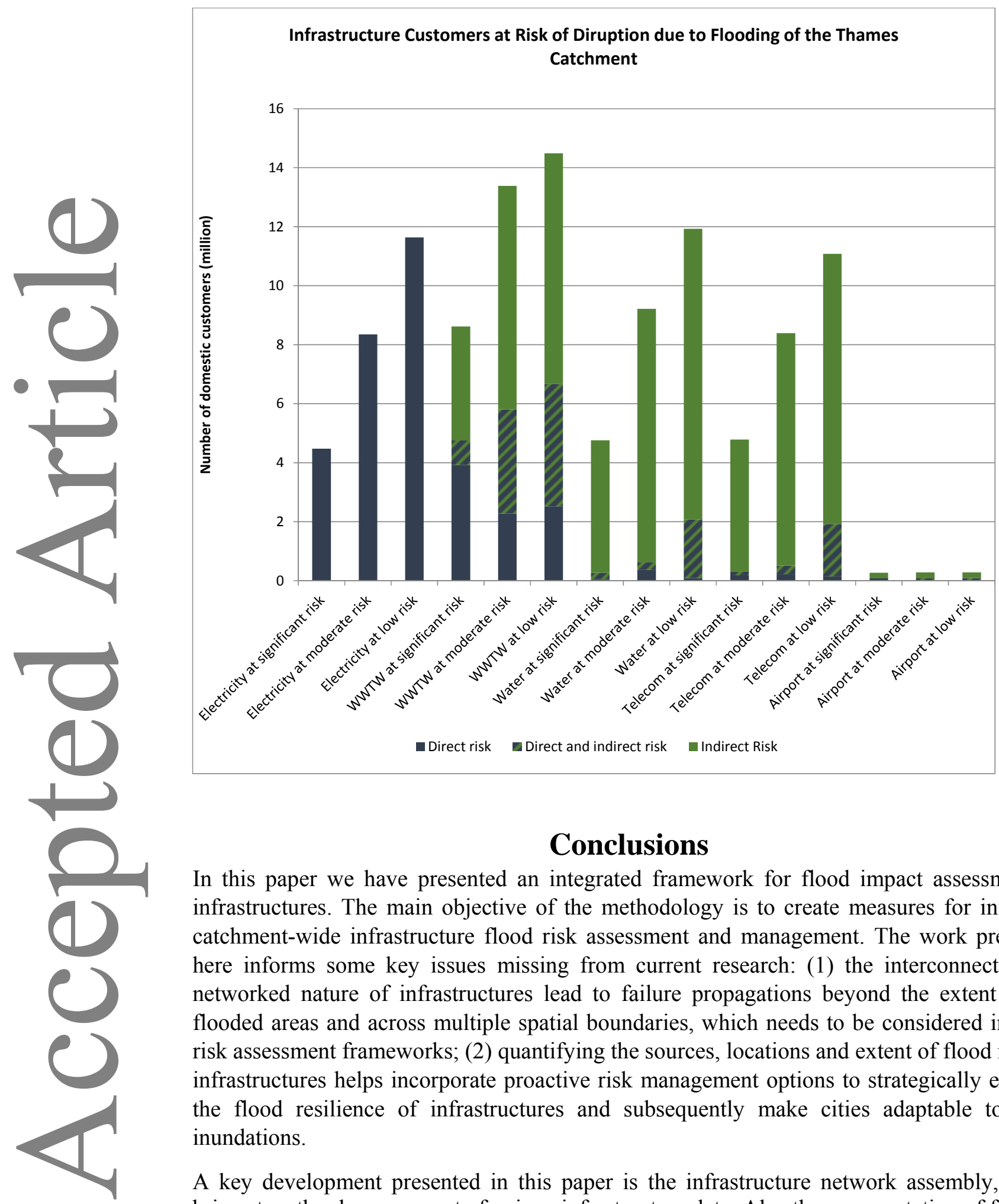

\section{Conclusions}

In this paper we have presented an integrated framework for flood impact assessment of infrastructures. The main objective of the methodology is to create measures for informed catchment-wide infrastructure flood risk assessment and management. The work presented here informs some key issues missing from current research: (1) the interconnected and networked nature of infrastructures lead to failure propagations beyond the extent of the flooded areas and across multiple spatial boundaries, which needs to be considered in flood risk assessment frameworks; (2) quantifying the sources, locations and extent of flood risks to infrastructures helps incorporate proactive risk management options to strategically enhance the flood resilience of infrastructures and subsequently make cities adaptable to flood inundations.

A key development presented in this paper is the infrastructure network assembly, which brings together large amount of unique infrastructure data. Also the representation of flows in terms of customers attached to different types of infrastructure assets gives us a common metric across all infrastructures, which is useful in creating disruption estimates. Here we have introduced the notion of estimating direct and indirect customer disruption estimates, which is generally not considered in such disruption analysis studies. The case study for the Thames catchment demonstrates the widespread nature of critical infrastructure disruption 
impacts. The set of critical infrastructures networks and assets assembled, i.e., electricity, water, waste, telecoms and airports, satisfy demands from the most populated regions in UK. Our analysis shows how these infrastructures could be potential disrupted due to the direct exposure to flooding and indirectly due to dependency on the electricity network. The aggregated sector level analysis presented here shows which sectors are more prone to flooding than others and which sectors are highly affected by electricity disruptions.

The models and analysis shown here provide several insights into understanding different aspects of the land use for flood risk management for critical infrastructures. As we have highlighted in the case-study the entire flood catchment and the infrastructure footprints extend across several LEP authority areas, which result in disruptive impacts across multiple governance boundaries. This reinforces the issue that flood risks are shared both upstream and downstream and resulting flood risk management requires overlap of the catchment areas and respective political and administrative actions (Seher and Löschner 2015). With infrastructures the risk sharing is bi-directional and has to be more widespread as several assets (e.g. airports) have much wider national-scale impacts from their localised failures (due to electricity in this study), affected governance at the national-scale.

Several research challenges and questions can be further developed from this analysis.

1. This analysis should be followed by much detailed site inspection and studies, to create better models and validate the data and magnitude of losses predicted by such analysis.

2. This work provides methodology for screening and prioritisation locations of vulnerable infrastructure assets in flood prone areas. Hence the question of 'where to invest in flood protection of critical infrastructures?' is answerable through such analysis. Mostly flood protection is determined through studies on household properties exposed to flooding, with little or no analysis done of prioritising flood protection for infrastructures (DfT, 2014).

3. From the spatial models and tools presented here further analysis can be developed to compare impacts amongst different LEP (or similar municipalities/regions). This is useful for understanding 'which economic/business regions are at more risk than others?', and 'where to budget and allocate macro-scale finances and resources?'

4. An interesting question for further research and inquiry is locating 'which infrastructure assets have cross-boundary impacts making them to collective responsibility of multiple administrations?'. The need for such an analysis has repeatedly arose in UK (ASC, 2014), and also has applicability to similar issues at the global scale.

\section{Acknowledgements}

The research reported in this paper was part of the UK Infrastructure Transitions Research Consortium (ITRC). The authors acknowledge funding of the work described here by the EPSRC (Engineering and Physical Sciences research Council of the UK) under Programme Grants EP/I01344X/1 and EP/N017064/1.

\section{References}

ASC (2014). Managing climate risks to well-being and the economy. ASC progress report. Adaptation Sub-Committee. 
AECOM (2008). Toward a City of Melbourne climate change adaptation strategy. A risk assessment and action plan discussion paper. Responding with resilience. Melbourne: AECOM.

Barredo, J. I. (2009). Normalised flood losses in Europe: 1970-2006. Natural Hazards and Earth System Sciences, 9(1), 97-104.

Bornschein, A., and Pohl, R. (2005). Lessons learned from the 2002 flood in Saxony, Germany. In Proceedings of the 40th Defra Flood and Coastal management Conference, York, England B (Vol. 5, pp. 3-1).

British Broadcasting Corporation (BBC) (2011). BT suffers huge broadband failure [online]. www.bbc.co.uk/news/technology-15154020 [Accessed 10 September 2015].

Cabinet Office (2010). Strategic framework and policy statement on improving the resilience of critical infrastrucuture to disruption from natural hazards. London, UK.

Civil Aviation Authority (CAA) (2010). Civil Aviation Authority: UK Airport Statistics.

Dawson R., Hall J., Sayers P., Bates P. and Rosu C. (2005). Sampling-based flood risk analysis for fluvial dike systems. Stoch Environ Res Risk Assess, 19, (6), 388-402.

Department of Energy and Climate Change (DECC) (2012). Digest of UK Energy Statistics (DUKES).

Department for Transport (DfT) (2014). Transport Resilience Review: A review of the resilience of the transport network to extreme weather event. Whitehall, London, UK.

EC (2007). Directive 2007/60/EC of the European Parliament and of the Council of 23 October 2007 on the assessment and management of flood risks. Official Journal of the European Union.

Emanuelsson, M. A. E., McIntyre, N., Hunt, C. F., Mawle, R., Kitson, J., and Voulvoulis, N. (2014). Flood risk assessment for infrastructure networks. Journal of Flood Risk Management, 7(1), 31-41.

Evans E., Hall J., Penning-Rowsell E., Sayers P., Thorne C. and Watkinson A. (2006). Future flood risk management in the UK. Proc Inst Civ Eng Water Manag, 159, (1), 53-61.

Gouldby B., Sayers P., Mulet-Marti J., Hassan M.A.A.M. and Benwell D. (2008). A methodology for regional-scale flood risk assessment. Proc Inst Civ Eng Water Manag, WM3, 169-182.

Hall, J. W., Dawson, R. J., Sayers, P. B., Rosu, C., Chatterton, J. B., \& Deakin, R. (2003). A methodology for national-scale flood risk assessment. In Proceedings of the Institution of Civil Engineers-Water Maritime and Engineering, 156(3), pp. 235-248.

HM Government (2011). Climate Resilient Infrastructure: Preparing for a Changing Climate. London, UK. 
HM Government. (2012) UK Climate Change Risk Assessment: Government Report. London: The Stationary Office.

Homeland Security (2013). NIPP 2013: Partnering for Critical Infrastructure Security and Resilience. Washington DC, US.

Institution for Civil Engineers (ICE) (2009). The State of the Nation: Defending Critical Infrastructure. Institution of Civil Engineers, London, UK.

Jongman, B., Winsemius, H. C., Aerts, J. C., de Perez, E. C., van Aalst, M. K., Kron, W., \& Ward, P. J. (2015). Declining vulnerability to river floods and the global benefits of adaptation. Proceedings of the National Academy of Sciences, 112(18), E2271-E2280.

Kalantari, Z., Nickman, A., Lyon, S. W., Olofsson, B., \& Folkeson, L. (2014). A method for mapping flood hazard along roads. Journal of environmental management, 133, 69-77.

Koks, E. E., Bočkarjova, M., Moel, H., \& Aerts, J. C. (2015). Integrated direct and indirect flood risk modeling: development and sensitivity analysis. Risk analysis, 35(5), 882-900.

Lee, D. T., and Schachter, B. J. (1980). Two algorithms for constructing a Delaunay triangulation. International Journal of Computer and Information Sciences, 9(3), 219-242.

Lewis, T. G. (2006). Critical infrastructure protection in Homeland Security: Defending a networked nation. Wiley.com.

McMillan, D. (2014). Disruptions at Gatwick Airport - Christmas Eve 2013. Report by David McMillan to the Board of Gatwick Airport Limited.

Merz B., Hall J., Disse M. and Schumann A. (2010). Fluvial flood risk management in a changing world. Nat Hazards Earth Sys Sci, 10, (3), 509-527.

National Grid (2012). Electricity Ten Year statement, UK electricity transmission. National Grid, UK.

Ordnance Survey (2013). OS Open Data: Mapping data and geographic information from Ordnance Survey. UK.

Pant, R., Hall, J.W., Barr, S., and Alderson, D. (2014). Spatial Risk Analysis of Interdependent Infrastructure Networks Subjected to Extreme Hazards. Vulnerability, Uncertainty and Risk, pp. 677-686.

Pant. R.. Hall. J.W. and Blainev. S.P.. 2016. Vulnerabilitv assessment framework for interdependent critical infrastructures: case-study for Great Britain's rail network. EJTIR, 16(1), pp.174-194.

Poljansek, K., Bono, F., Gutierrez, E. (2010). GIS-based method to assess seismic vulnerability of interconnected infrastructure: A case of EU gas and electricity networks. $E U$ JRC 24275.

Rinaldi, S. M. (2004). Modeling and simulating critical infrastructures and their interdependencies. In: System sciences, 2004. Proceedings of the 37th annual Hawaii international conference on. IEEE, pp. 8-pp. 
Rinaldi, S. M., Peerenboom, J. P., Kelly, T. K. (2001). Identifying, understanding, and analyzing critical infrastructure interdependencies. Control Systems, IEEE 21 (6), 11-25.

Seher, W., and Löschner, L. (2015). Vertical and Horizontal Risk-Sharing in Flood-Related Planning. Challenges for Governance Structures in Urban and Regional Development, 301.

Thacker, S., Pant R., and Hall, J. W. (2015). System-of-Systems Formulation and Disruption Analysis for Multi-Scale Critical National Infrastructures. Reliability Engineering and System Safety. In Review.

Thaler, T. (2014). Developing partnership approaches for flood risk management: implementation of inter-local co-operations in Austria. Water International, 39(7), 10181029.

Thaler, T. A., Priest, S. J., \& Fuchs, S. (2016). Evolving inter-regional co-operation in flood risk management: distances and types of partnership approaches in Austria. Regional Environmental Change, 16(3), 841-853.

Thieken, A.H., Ackermann, V., Elmer, F., Kreibich, H., Kuhlmann, B., Kunert, U., Maiwald, H., Merz, B., Müller, M., Piroth, K. and Schwarz, J. (2008). Methods for the evaluation of direct and indirect flood losses. In Proceedings of the 4th International Symposium on Flood Defence: Managing Flood Risk, Reliability and Vulnerability, Toronto, ON, Canada (Vol. 68, p. 110).

Wheater, H., \& Evans, E. (2009). Land use, water management and future flood risk. Land Use Policy, 26, S251-S264.

Zischg, A., Fuchs, S., Keiler, M., \& Stötter, J. (2005b). Temporal variability of damage potential on roads as a conceptual contribution towards a short-term avalanche risk simulation. Natural Hazards and Earth System Science, 5(2), 235-242. 